\title{
LAGROU, Els. 2009. Arte Indígena no Brasil: agência, alteridade e relação. Belo Horizonte: C/ Arte. 127p.
}

Christiane A. Tragante O livro de Els Lagrou Arte Indígena no Brasil foi lançado em 2009 pela editora C/

UFSCAR Arte, como parte da Coleção Didática que, junto com outras obras, apresentam as artes no Brasil. Apesar do título que carrega, não tem como objetivo, como coloca a autora na introdução, oferecer um panorama das artes indígenas aqui existentes. Se o leitor, porém, atentar-se para o subtítulo encontrará aí o recorte escolhido pela autora: agência, alteridade e relação que perpassam este "ensaio teórico que visa a realçar o que a arte indígena possui de específico e fascinante" (p. 9).

Em todo o livro, a autora faz intervenções que conduzem o leitor a refletir sobre o diálogo entre a arte indígena e a ocidental. No primeiro capítulo, denominado Arte ou Artefato? Agência e significado nas artes indígenas, esse diálogo ganha peso, pois, é por meio das diferenças com a arte ocidental que a autora nos apresenta a arte indígena. Els Lagrou elege dois problemas centrais que evidenciam um aparente hiato entre esses dois universos: "a tradicional diferença entre arte e artefato e o papel da inovação da produção selecionada como 'artística'" (p.11). Como falar, neste caso, de arte e estética no Brasil e dar conta da produção indígena, a despeito destas diferenças marcantes? Uma questão como essa leva consigo outros problemas de ordem epistemológica e teórica, todavia, Els Lagrou pôde respondê-las por ancorarse teórico-metodologicamente na antropologia da arte introduzida pelo antropólogo Alfred Gell.

Em Art and Agency (1998), Gell se preocupa em fazer uma antropologia da arte que trate precisamente das relações sociais que estão envoltas ao objeto, de forma que a arte se torne ação afastando-se, com isso, da tradição simbólica ou representacionalista para a qual a arte serviria à classificação de fenômenos sociais para além do universo artístico. Nas palavras de Gell, "in place of symbolic communication, I place all the emphasis on agency, intention, causation, result and transformation" (Idem: 6). Este deslocamento, que vai do estudo do significado para a eficácia do artefato, segundo Lagrou, "tem um rendimento particularmente 
interessante no contexto da análise dos artefatos e imagens ameríndias porque permite fugir do segundo dos pressupostos que definem a discussão no campo das artes no Ocidente" ( $p: 32$ ). Ao colocar a ênfase na agência, Gell se distancia da tradição ocidental e da concepção estética de arte e permite um diálogo profícuo entre os objetos da arte ocidental e não-ocidental. Se a estética é marcadamente discriminatória e não pode servir aos propósitos de comparação pelo seu caráter de julgo, como marcou Peter Gow em Aesthetics is a cross-cultural category (1993), então a saída vista por Gell é pensar as intencionalidades que os objetos incitam no milieu. Desta forma, independente de pertencerem a este ou aquele lugar, o que está em jogo não é mais uma tradição artística, mas uma rede de intenções e causalidades.

A proposta de tratar simetricamente objetos de arte ocidental e não-ocidental é evidenciada no texto Vogel's net: traps as artworks and artworks as traps (2006) que tem como mote uma rede de pesca Azande exposta no Center for African Art em Nova lorque no ano de 1988, por Susan Vogel, curadora e antropóloga. Neste texto, Gell discute com o filósofo e crítico de arte americano Arthur Danto que, no catálogo da exposição, afirma não estar convencido de que a rede possa ser considerada um objeto de arte uma vez que ela constitui um artefato. Segundo Danto e a teoria interpretativista, a especificidade da arte contemporânea encontra-se em produzir objetos significativos que, portanto, não são simplesmente técnicos. Gell, porém, utilizando-se de exemplos etnográficos e obras de arte, se encarrega de provar que até simples armadilhas podem vir a ser significativas e, portanto, poderiam ser consideradas como objetos de arte. Uma armadilha, como mostra Gell, pode ser vista como um texto que fala sobre o caçador, a presa, o comportamento do animal, a violência, dentre outros significados que as mais diversas etnografias podem esclarecer. Sendo assim, a exposição da rede é legítima na visão de Gell, pois:

(...)these traps communicate the idea of a nexus of intencionalities between hunters and prey animals, via material forms e mechanisms. I would argue that this evocation of complex intentionalities is in fact what serves to define artworks, and that, suitably framed, animals traps could be made to evoke complex intuitions of being, otherness, relatedness (Gell op. cit: 203).

Um conjunto de intencionalidades, portanto, é a maneira como Gell define um objeto de arte. Desta forma, não há mais distinção entre arte e artefato, arte ocidental ou indígena, ambas podem ser vistas, conceitualmente, como correspondentes. Se objetos indígenas cristalizam ações, valores e ideias, como na arte conceitual, ou provocam apreciações valorativas da categoria dos tradicionais conceitos de beleza e perfeição formal como entre nós, porque sustentar que conceitualmente esses povos desconhecem o que nós conhecemos como 'arte'? (Lagrou 2009: 13).

Destarte, com tal aporte teórico e conceitual, Els Lagrou termina o primeiro capítulo legitimando o campo para o leitor à medida que vai apresentando os dados etnográficos que só se retroalimentam com a teoria. Com exemplos da arte Kaxinawa, sobre a qual a antropóloga já discorreu com maestria em sua obra $A$ fluidez da forma: arte, alteridade e agência em uma sociedade amazônica (2007), Els encerra o capítulo denotando a particularidade produtiva e performativa dos desenhos Kaxinawa - os desenhos não são representativos, seu sentido encontra-se na sua funcionalidade; eles contribuem com a produção dos corpos e das pessoas - tema sobre o qual discorrerá 
no capítulo seguinte.

Em Corpos e Artefatos, o segundo capítulo do livro, Els Lagrou nos apresenta a produção dos corpos ameríndios consoantes à produção dos artefatos. Desde que a antropologia passou a enfatizar aquilo que as sociedades indígenas brasileiras têm de original, como nos revelou o texto de Anthony Seeger, Roberto Da Matta e Eduardo Viveiros de Castro, A construção da pessoa nas sociedades indígenas brasileiras (1979), a construção da pessoa e a corporalidade passaram a ser entendidas como via não-etnocentrica informadora das cosmologias em questão (p. 26). O esforço de Lagrou neste ponto é mostrar ao leitor que, se é necessário entender a ideia de corporalidade para atingir tais cosmologias, então não há como escapar aos artefatos, pois "artefatos são como corpos e corpos como artefatos" (Lagrou 2009: 39).

Os exemplos utilizados pela autora movem o leitor que muda de perspectiva ao pensar os corpos/artefatos. A autora nos apresenta, por meio de trechos de etnografias, particularidades sobre o tema. Entre os Kaxinawa, por exemplo, o foco está nas questões relativas à decoração dos corpos, seja por meio das pinturas corporais ou das miçangas, revelando que "a relação entre capacidades interiores [como durabilidade e dureza] e decoração exterior [com miçangas, dentes, sementes e desenhos] não é de reflexão, mas interação" (Idem: 54). 0 trato dado aos artefatos influencia diretamente na fabricação e manutenção dos corpos; corpos são tratados como artefatos e vice-versa.

O tema já aludido no primeiro capítulo, sobre a diferença entre as artes ocidental e não-ocidental, é retomado no capítulo terceiro, sob o nome $A$ arte ligando mundos: alteridade e autenticidade no mundo das artes. Nesta parte do livro, a autora reflete sobre a arte indígena no contexto extra-étnico, dando realce aos problemas museológicos. O que acontece quando objetos como máscaras, panelas, dentre outros artefatos, se encontram em locais nãoíndígenas de exposição pública? Problemas como este remetem mais uma vez, ao nosso modo de conceber o que seja arte: estética, distinção entre arte e artefato, inovação; todas características da arte ocidental que entram no jogo da interculturalidade.

Segundo a própria autora, na introdução de Arte primitiva em centros civilizados (2000) de Sally Price, já nos é claro como às peças "primitivas" são imputados valores ocidentais, sem que os verdadeiros produtores sejam consultados sobre sua estética ou sua percepção (p.11). Els Lagrou quer mostrar ao leitor que, para que possamos incorporar objetos provenientes de outros contextos de produção, apropriação e avaliação no campo da apreciação estética metropolitana, é necessário, primeiramente, compreender as cosmologias às quais esses objetos pertencem e, segundo, mudar a perspectiva conceitual sobre a arte. Assim, não é possível buscar inovação e ruptura em objetos concebidos por sociedades que valorizam uma história da conservação e da continuidade; bem como não podemos esperar que a construção da pessoa do artista seja a mesma em contextos díspares. Mesmo perante a tais diferenças, Lagrou argumenta em favor de uma definição mais ampla de "arte":

(...) derivada da palavra ars em Latim e anterior à especialização que a palavra sofreu durante o lluminismo. Este conceito se refere à capacidade consciente e intencional de produzir objetos e ao conjunto de regras e técnicas que o pensamento usa para representar a realidade e agir sobre ela (Lagrou 2009: 69). 
Apesar do argumento de Lagrou, a questão continua muito atual para antropólogos, curadores, museólogos, críticos de arte, e eu acrescentaria aqui, já que o livro tem caráter didático, professores e educadores. Em que medida é possível fruir esses objetos no contexto extra-étnico? Que valores são a eles atribuídos tanto por quem os observa, quanto para os próprios indígenas quando estão, por exemplo, em uma exposição de arte? Els nos lembra, citando o trabalho de Aristóteles Barcelos Neto, Apapaatai: ritual de máscaras no Alto Xingu (2008), que as máscaras fabricadas pelos Wauja passavam por um processo de renegociação quando os objetos eram destinados à performance fora da aldeia e às coleções. Uma vez que as máscaras eram extensões dos corpos dos apappatai - os seres-espíritos - elas não poderiam ficar longe da aldeia sem que houvesse uma "desubjetivização"; por esse motivo chegavam à exposição modificadas e tinham, com isso, "perdido grande parte do seu poder de agência" (Lagrou 2009:75).

O quarto capítulo do livro trata do desenho e da pintura corporal. A autora, através de vários exemplos, põe em foco o caráter performativo dos grafismos. Apesar de comparar tal performance com a fugacidade de obras contemporâneas - como os happenings - os exemplos encontrados entre os Kaxinawa, os Asurini, os Wauja e outros ameríndios demonstram que, neste contexto, a arte é tão intangível a ponto de passar quase desapercebida até para o antropólogo em campo, de forma que não é possível percebê-la somente estando por perto. A experiência dos nativos em relação à arte "só pode ser entendida se captarmos a maneira como o pensamento nativo concebe a realidade" (Idem: 82). Assim, o que Els parece comunicar continuamente neste último capítulo, é que não há como compreender, entender ou até mesmo fruir a arte indígena, seja ela os objetos, os artefatos, a pintura corporal, ou estando ela em sua forma mais fluida, sem considerar as cosmologias de concepção e organização do mundo nativo (Idem: 101).

Na Conclusão, Lagrou relata que, com o livro, visava uma revolução copernicana para a arte, da maneira como fez Clastres para a política. É necessário, com isso, inverter a perspectiva, olhando como especificidade o que antes era visto como falta.

Se olharmos para a Arte como uma arte de construir mundos, e não mais como um fenômeno a ser distinguido do artefato - uma esfera do fazer associada ao extraordinário, que para manter sua sacralidade precisa ser separada do cotidiano - a relação cognitiva é invertida (Idem: 104).

Com tal mudança de perspectiva, Els Lagrou aspira, conceitualmente, livrar a arte do peso da tradição ocidental (histórica e institucionalmente) - já que ela passa a ser aquilo que age, cria e transforma o mundo - e, com isso, possibilitar a "coexistência e sobreposição de diferentes mundos que não se excluem mutuamente" (Idem: 105).

Cabem ao fim desta resenha algumas últimas considerações. Como foi marcado no início deste texto, o livro em questão tem caráter didático, apresentando, ao fim, Orientações Pedagógicas e um Glossário. Porém, salvo a indicação das orientações pedagógicas na folha de rosto, durante todo o texto não há menção ao caráter didático/ educacional do livro. Na Introdução, Lagrou refere-se ao objetivo do ensaio que, segundo ela, "visa a ensinar um modo de entender e olhar para as artes indígenas" (Lagrou 2009: 9). De fato, o livro é deveras contributivo; é rico 
em exemplos e imagens e possibilita ao leitor uma inversão de perspectiva, fornecendo um olhar mais alargado sobre as artes no Brasil. Contudo, qual leitor estaria em jogo? Se o livro se volta a um público que não precisa ter, necessariamente, alguma "iniciação" em antropologia, então, como compreender uma discussão tão densa que empreende uma "revolução copernicana para a arte" sem a matriz antropológica? Acredito que as discussões em antropologia não devem encerrar-se em seu próprio campo; o que coloco em questão é o formato do texto em relação às orientações pedagógicas. Lagrou faz uso de comparações entre os dois sistemas de arte, porém, parece não ter havido extenso diálogo com Lucia Gouvêa Pimentel e William Resende Quintal - os responsáveis pela parte didática. O glossário deve servir ao leitor não-antropólogo, pois apresenta termos bastante elementares, todavia, frente à densidade da discussão, as glosas se tornam prescindíveis, até mesmo porque elas não são somente notas explicativas mas, em sua maioria, são conceitos.

Assim, termino com um apelo aos antropólogos. Frente à responsabilidade que a área de Educação Artística tomou com a obrigatoriedade do ensino de História e Cultura Afro-Brasileira e Indígena a partir da Lei No. 11.645, de 10 de Março de 2008, necessitamos de um diálogo intenso, absorvente. Clarice Cohn nos conta em sua resenha Um romance etnográfico, que Margareth Mead costumava explicar a penetração de suas análises dizendo que escrevia em inglês, e não em antropologuês (Cohn 2008:178). Este talvez tenha sido um grande desafio para Lagrou, porém não cabe somente a ela: coexistir e sobrepor esses diferentes mundos - antropólogos e não antropólogos - de modo que eles não se excluam mutuamente.

Christiane A. Tragante é mestranda pelo Programa de Pós Graduação em Antropologia Social da UFSCAR, bolsista CAPES e graduada em Educação Artística com Habilitação em Artes Plásticas pela UNESP. 